\title{
INFECCIÓN DEL TRACTO RESPIRATORIO HUMANO POR Lophomonas spp.
}

\section{HUMAN RESPIRATORY TRACT INFECTION DUE TO Lophomonas spp.}

\author{
Rito Zerpa $a^{1,2, a}$, Elsa Oré ${ }^{1, b}$
}

Lophomonas sp., es un protozoario multiflagelado anaerobio, con dos especies reconocidas: Lophomonas blattarum y Lophomonas striata. Se ha descrito como comensales en el tracto digestivo de cucarachas: Periplaneta americana, Blatta orientales y Blatta germanica; también en termitas y ciertas aves como las avutardas. En la literatura mundial todavía hay escasos reportes de este protozoario zoonótico emergente en infecciones en humanos; descrito afectando principalmente al tracto respiratorio inferior en pacientes con enfermedad pulmonar grave en niños y adultos $\mathrm{y}$, recientemente, en adultos con asma bronquial; en nuestro medio Lophomonas sp. se ha reportado en el tracto respiratorio de niños con neumonía, principalmente de unidad de cuidados intensivos (UCI) ${ }^{(1)}$; niños con cuadros coqueluchoides y coinfección con Bordetella pertussis, así como en pacientes adultas con asma bronquial (2).

Recientemente, en un artículo de China, Mu etal. ${ }^{(3)}$ concluye que: En los últimos 20 años, los casos diagnosticados como infección pulmonar por Lophomonas blattarum en nuestro país, fueron mal diagnosticados. Actualmente, no hay evidencia para mostrar a Lophomonas blattarum como un patógeno que pueda causar infección pulmonar. El objetivo de la presente galería es mostrar videos de Lophomonas spp. como evidencias de infección de este protozoario en muestras del tracto respiratorio de niños y adultos con las enfermedades mencionadas, en el Instituto Nacional de Salud del Niño; asimismo, en aspirado traqueal de una adulta con asma bronquial (de un hospital de adultos) y de lavado broncoalveolar de un adulto con sospecha de tuberculosis en el 2013.

El diagnóstico de laboratorio de Lophomonas spp. se realizó en el Servicio de Microbiología con el examen microscópico directo en fresco o en montaje húmedo con objetivos de 10X, 20X y 40X, observándose al protozoario de forma esférica, ovoide o piriforme (15 a $40 \mu \mathrm{m})$ con múltiples flagelos en un polo y en movimiento, característicos (Figura y videos 1 al 9), diferenciándose en videos de la morfología de células bronquiales ciliadas (Figura y video 10); se presenta también un conglomerado de Lophomonas spp. en un aspirado traqueal de una adulta con cuadro asmatiforme (Figura y video 11). Respecto a la transmisión al humano, se ha planteado una hipótesis de que la forma quística del parásito es la forma infectante (vía inhalatoria o por líquidos contaminados), realizándose la excistación y liberación de los trofozoitos en las vías respiratorias ${ }^{(4)}$; su reproducción es por fisión binaria. Respecto al tratamiento, se emplea, principalmente, metronidazol en dosis de 7,5

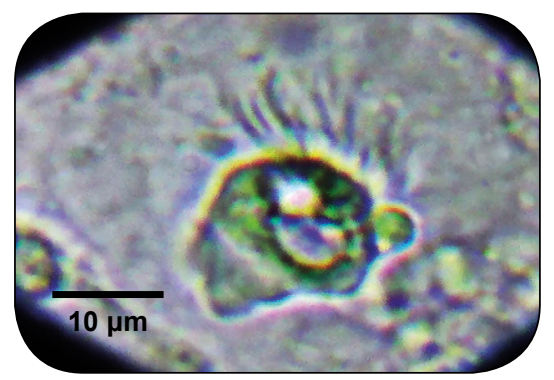

Figura 1. Lophomonas en muestra de aspirado traqueal de un niño con neumonía. Video: https://youtu.be/ksfuk6u_nGs

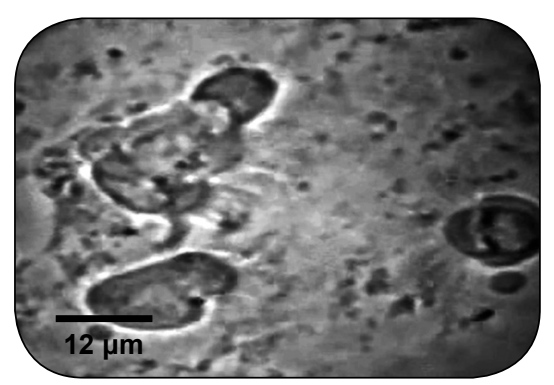

Figura 2. Lophomonas en muestra de aspirado nasofaríngeo de un niño con cuadro coqueluchoide. Video: https://youtu. be/rSIUeeTz1uo

\footnotetext{
Servicio de Microbiología, Instituto Nacional de Salud del Niño. Lima, Perú

Instituto de Medicina Tropical “Daniel A. Carrión”, Universidad Nacional Mayor de San Marcos. Lima, Perú.

Médico patólogo clínico; ${ }^{\mathrm{b}}$ Tecnólogo médico

Recibido: 06/10/2016 Aprobado: 23/11/2016
}

Citar como: Zerpa R, Ore E. Infección del tracto respiratorio humano por Lophomonas spp. Rev Peru Med Exp Salud Publica. 2016;33(4):827-8.doi: 10.17843/ rpmesp.2016.334.2572 


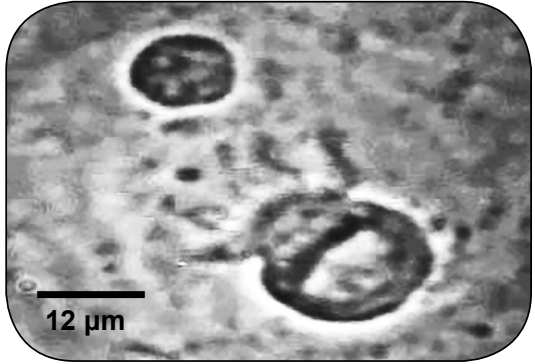

Figura 3. Lophomonas en muestra de aspirado nasofaríngeo de un niño con cuadro coqueluchoide.

Video: https://youtu.be/SWLYqY_dZ70

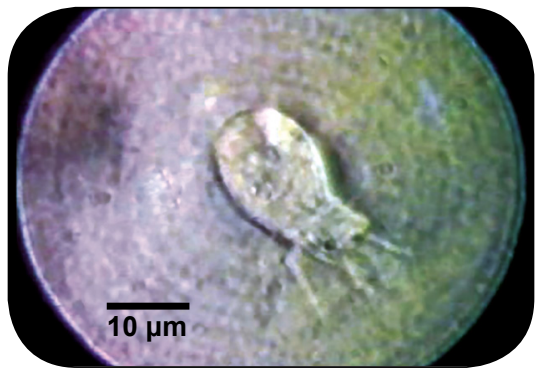

Figura 6. Lophomonas $s p$. en muestra de aspirado traqueal, preparación en montaje húmedo.

Video: https://youtu.be/RpzErwInzmQ

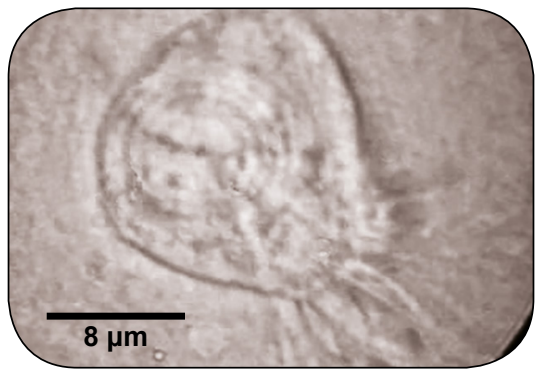

Figura 9. Lophomonas a mayor aumento. Video: https://youtu.be/8F3dtD73Tq0

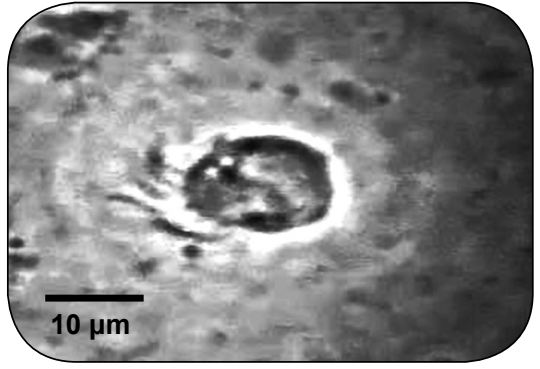

Figura 4. Lophomonas en muestra de aspirado nasofaríngeo de un niño con cuadro coqueluchoide.

Video: https://youtu.be/wK1aDNLBI3c

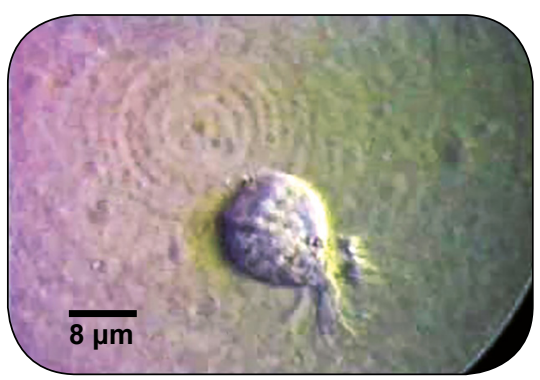

Figura 7. Lophomonas $s p$. en muestra de aspirado traqueal, preparación en montaje húmedo.

Video: https://youtu.be/lsC27JBGurw

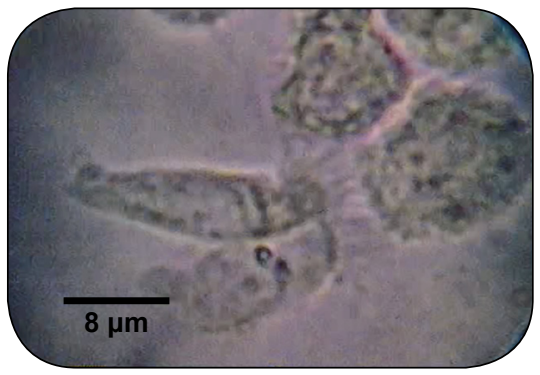

Figura 10. Dos células bronquiales con sus cilios en movimiento.

Video: https://youtu.be/OgZEgZOu62U

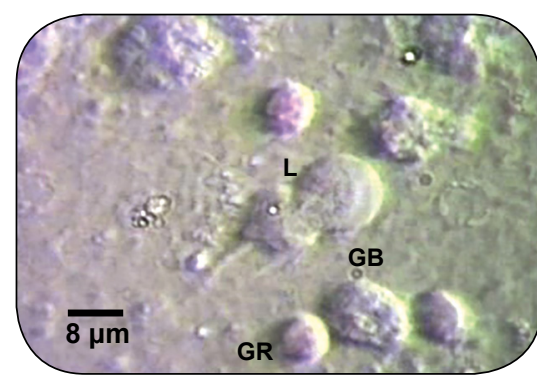

Figura 5. Lophomonas $(\mathrm{L})$ con sus flagelos en movimiento entre leucocitos (GB) y hematíes (GR), en muestra de aspirado traqueal de un niño con neumonía.

Video: https://youtu.be/LlwygXB4314

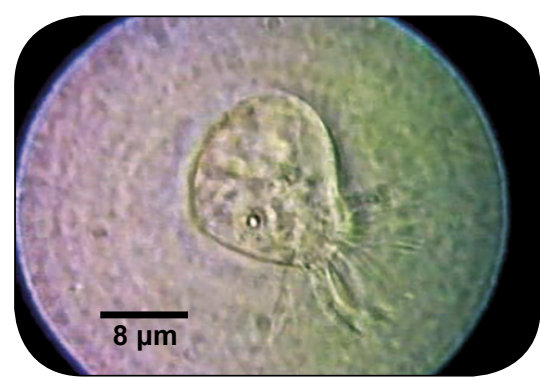

Figura 8. Lophomonas sp. en muestra de aspirado traqueal, preparación en montaje húmedo.

Video: https://youtu.be/HK4CO-OZXkY

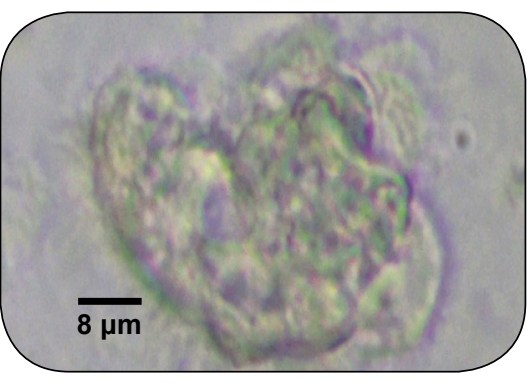

Figura 11. Conglomerado de Lophomonas de aspirado traqueal de una adulta con cuadro asmatiforme.

Video: https://youtu.be/vL5QctvTLpQ $\mathrm{mg} / \mathrm{kg}$ en la población pediátrica y en adultos $500 \mathrm{mg}$ cada $8 \mathrm{~h}$, oralmente por 7-10 días; otra alternativa es el tinidazol.

\section{REFERENCIAS BIBLIOGRÁFICAS}

1. Zerpa R, Oré E, Patiño L, Espinoza Y. Hallazgo de Lophomonas sp. en secreciones del tracto respiratorio de niños hospitalizados con enfermedad pulmonar grave. Rev Peru Med Exp Salud Publica. 2010 Oct-Dec;27(4):575-7.

2. Zerpa R, Oré E, Quispe C, Patiño L, Alvarado M, Wong P. Lophomonas sp. in respiratory tract secretions in hospitalized children with pneumonia and Bordetella pertussis coinfection. ASTMH 62nd Annual Meeting 2013, Washington, DC.
3. Mu XL, Shang Y, Zheng SY, Zhou B, Yu B, Dong XS, Cao ZL, Jiang N, Sun KK, Chen YC, Xi W, Gao ZC. A study on the differential diagnosis of ciliated epithelial cells from Lophomonas blatarum in bronchoalveolar lavage fluid. Zhonghua Jie He He Hu Xi Za Zhi. 2013 Sep;36(9):646-50.

4. Martínez-Girón $\mathrm{R}$, van Woerden HC. Lophomonas blattarum and bronchopulmonary disease. J Med Microbiol. 2013 Nov;62(Pt 11):1641-8. doi: 10.1099/ jmm.0.059311-0

Correspondencia: Rito Zerpa Larrauri

Dirección: Av. Rio Marañón 436, Los Olivos. Lima, Perú.

Teléfono: (+511) $648-1113$

Correoelectrónico:rzerpa43@yahoo.com 